\title{
Emulsion Templating of Poly(lactic acid) Particles: Droplet Formation Behavior
}

\author{
Goran T. Vladisavljević, ${ }^{*},, \|$ Wynter J. Duncanson, ${ }^{\ddagger}$ Ho Cheung Shum, ${ }^{\S}$ and David A. Weitz ${ }^{\ddagger}$ \\ ${ }^{\dagger}$ Department of Chemical Engineering, Loughborough University, Loughborough, LE11 3TU, United Kingdom \\ ${ }^{\ddagger}$ Department of Physics, Harvard University, Cambridge, Massachusetts 02138, United States \\ ${ }^{\S}$ Department of Mechanical Engineering, University of Hong Kong, Pokfulam Road, Hong Kong \\ "Vinča Institute of Nuclear Sciences, University of Belgrade, PO Box 522, Belgrade, Serbia
}

ABSTRACT: Monodisperse poly(DL-lactic acid) (PLA) particles of diameters between 11 and $121 \mu \mathrm{m}$ were fabricated in flow focusing glass microcapillary devices by evaporation of dichloromethane (DCM) from emulsion droplets at room temperature. The dispersed phase was $5 \%(\mathrm{w} / \mathrm{w})$ PLA in DCM containing $0.1-2$ $\mathrm{mM}$ Nile Red and the continuous phase was $5 \%(\mathrm{w} / \mathrm{w})$ poly(vinyl alcohol) in reverse osmosis water. Particle diameter was 2.7 times smaller than the diameter of the emulsion droplet template, indicating very low particle porosity. Monodisperse droplets have only been produced under dripping regime using a wide range of dispersed phase flow rates $\left(0.002-7.2 \mathrm{~cm}^{3} \cdot \mathrm{h}^{-1}\right)$, continuous phase flow rates $(0.3-$ $\left.30 \mathrm{~cm}^{3} \cdot \mathrm{h}^{-1}\right)$, and orifice diameters $(50-237 \mu \mathrm{m})$. In the dripping regime, the ratio of

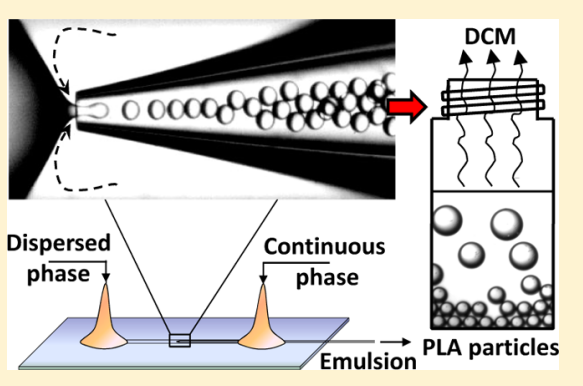
droplet diameter to orifice diameter was inversely proportional to the 0.39 power of the ratio of the continuous phase flow rate to dispersed phase flow rate. Highly uniform droplets with a coefficient of variation (CV) below $2 \%$ and a ratio of the droplet diameter to orifice diameter of $0.5-1$ were obtained at flow rate ratios of 4-25. Under jetting regime, polydisperse droplets (CV $>6 \%$ ) were formed by detachment from relatively long jets (between 4 and 10 times longer than droplet diameter) and a ratio of the droplet size to orifice size of $2-5$.

\section{INTRODUCTION}

In recent years, there has been an increasing interest in the fabrication and use of microspheres composed of biodegradable polymers. $^{1-3}$ These microspheres are usually emulsion templated particles that have been formed through a combination of emulsification of a polymer/organic solvent mixture in an aqueous surfactant solution and subsequent organic solvent removal. Removal of solvent can be achieved either by the ambient solvent extraction/evaporation method ${ }^{4}$ or by the freezing method, where the solvent to be removed is frozen and gradually heated under vacuum, leaving behind precipitated solid microspheres. ${ }^{5}$ Biodegradable microparticles are of interest primarily for medical and pharmaceutical applications, where they have been used for the encapsulation and controlled release of a wide range of pharmaceutical actives (rifampicin, ${ }^{6}$ buserilin, ${ }^{7}$ paclitaxel, ${ }^{8}{ }^{2}$ tetracycline, ${ }^{9}$ etc.), encapsulation of biological actives such as plasmid DNA, ${ }^{10,11}$ ultrasound and molecular imaging, ${ }^{12,13}$ ultrasound-triggered drug release, ${ }^{14}$ cell cultivation in tissue engineering, ${ }_{17,16}$ fabrication of scaffolds for bone tissue repair applications, ${ }^{17,18}$ and fabrication of composite coatings for implantable devices. ${ }^{19,20}$ The most commonly used biodegradable synthetic polymers for these applications are poly(lactic acid) (PLA) and poly(lactic-co-glycolic) acid (PLGA), since they both have favorable properties such as good biocompatibility, biosorbability, and mechanical strength. ${ }^{21}$

Monodisperse particles are favorable in drug delivery and ultrasound imaging applications because they exhibit controlled in vivo behavior such as predictable biodegradation rate, drug release profile, and acoustic response. Precision generation of droplets is a crucial step in fabrication of particles by emulsification/solvent evaporation method, because monodisperse particles can only be produced from monodisperse droplets. As a consequence of inhomogeneous shear field during processing, the conventional methods of droplet generation such as spray drying, ${ }^{22}$ sonication, ${ }^{11,23}$ high-shear rotor/stator mixing, ${ }^{8,15,24}$ and high-pressure homogenization ${ }^{25}$ result in polydisperse PLA or PLGA particles whose mean size cannot be precisely controlled.

As a departure from the traditional "top-down" emulsification approach, where particle size is controlled by turbulence and smaller droplets are formed by reducing the size of larger droplets, a number of "drop-by-drop" emulsification methods are currently being studied, where particle size is controlled by internal geometry and small droplets are directly formed by injecting one liquid through a micronozzle/channel into another immiscible liquid. Several such methods have been used in the production of biodegradable microspheres such as inkjet printing, ${ }^{3,26}$ microchannel emulsification, ${ }^{27}$ membrane emulsification, ${ }^{6}$ jet acoustic excitation, ${ }^{4}$ and planar microfluidic devices. $^{28,29}$ Membrane emulsification produces emulsions with high coefficients of variation of particle sizes $(\mathrm{CV}>10 \%)$, and

Received: May 22, 2012

Revised: July 18, 2012

Published: August 3, 2012 
silicon microchannel plates and inkjet nozzles are relatively expensive to fabricate. On the other hand, planar (twodimensional) flow focusing microfluidic devices are cheap and disposable, but droplets typically contact the walls of the outlet channel due to its rectangular cross section, which can damage the newly formed liquid/liquid interface or cause wetting problems. $^{30}$

The purpose of this study was to investigate a novel approach to the fabrication of monodisperse PLA microparticles with controllable size based on emulsification in an axisymmetric flow focusing glass capillary device ${ }^{31}$ followed by solvent evaporation. The main emphasis was to elucidate the effects of phase flow rates and geometry of the device on the droplet formation behavior. In an axisymmetric (three-dimensional) flow focusing device, the dispersed phase is entirely surrounded by the continuous phase irrespective of the flow rates due to circular cross section of the outlet channel. Although glass microcapillary devices are not as easily replicated as those made from moldable polymers such as poly(dimethylsiloxane) (PDMS), we have chosen borosilicate glass as a construction material because glass is more chemically robust than PDMS, does not swell, and has more stable surface properties. The surface properties of PDMS can change upon exposure to organic solvents. In addition, it was noticed that the hydrophilic (plasma oxidized) PDMS rapidly becomes hydrophobic upon exposure to dichloromethane. ${ }^{30}$

\section{EXPERIMENTAL SECTION}

Materials for Emulsion Preparation. The dispersed phase of oilin-water $(\mathrm{O} / \mathrm{W})$ emulsions consisted of a mixture of $5 \%(\mathrm{w} / \mathrm{w})$ poly(DL-lactic acid) (PLA) (Polysciences Europe GmbH, 15000 $\left.\mathrm{g} \cdot \mathrm{mol}^{-1}\right), 95 \%(\mathrm{w} / \mathrm{w})$ dichloromethane (DCM) (Aldrich, purity 99+ $\%)$, and $0.1-2 \mathrm{mM}$ Nile Red dye (Sigma-Aldrich). The viscosity and density of this mixture at $298 \mathrm{~K}$ was $1.02 \mathrm{mPa} \cdot \mathrm{s}$ and $1310 \mathrm{~kg} \cdot \mathrm{m}^{-3}$, respectively. The continuous phase was a $5 \%(\mathrm{w} / \mathrm{w})$ aqueous solution of polyvinyl alcohol (Sigma-Aldrich, $87-89 \%$ hydrolyzed) with a viscosity of $4.04 \mathrm{mPa} \cdot \mathrm{s}$ at $298 \mathrm{~K}$. The interfacial tension between the two phases measured using a Krüss DSA-100 pendant drop tensiometer at $298 \mathrm{~K}$ was $2.26 \mathrm{mN} \cdot \mathrm{m}^{-1}$.

Preparation of the Microfluidic Device. A round borosilicate capillary tube (Intracel; inner diameter $580 \mu \mathrm{m}$, outer diameter $1 \mathrm{~mm}$ ) was pulled using a Flaming/Brown micropipette puller (Sutter Instruments, model P-97). Upon pulling, the tip was precisely cut using a Narishige model MF-830 microforge to obtain an entry diameter, $D_{o}$, between 50 and $240 \mu \mathrm{m}$. To enhance hydrophilicity of the glass surface and minimize wetting with DCM drops, the tip was treated with 2-[methoxy(polyethylenoxy)propyl] trimethoxysilane solution (Gelest Inc.) followed by drying in a compressed air stream. The treated capillary was then partly inserted into a square glass tube (AIT Inc.) of internal side length $1.05 \mathrm{~mm}$ and fixed into position onto a microscopic slide using epoxy resin adhesive. Hypodermic needles with polypropylene hub were glued over both ends of the square glass tubing to act as separate tube connectors for the oil and water phase, while the exposed end of the round glass capillary was connected to a sample collection tube.

Emulsion Experiments. A microfluidic device, set on the stage of an inverted Leica DM-IRBE microscope, was connected to gastight syringes containing the continuous and disperse phases via medical tubing. Each phase was pumped into the device by a separate programmable Harvard Apparatus PHD 22/2000 syringe pump. The process of droplet formation was recorded digitally using a Phantom V5.1 high-speed camera at 800-2000 frames per second. Frames of the high-speed video footage were analyzed using ImageJ v.1.44 software to estimate droplet diameter, $D_{\mathrm{d}}$, and the rate of droplet formation. The effects of varying continuous and dispersed phase flow rates and orifice diameter, $D_{\mathrm{o}}$, on the droplet formation behavior were studied. The dispersed phase flow rates studied were between 0.02 and
$7.2 \mathrm{~cm}^{3} \cdot \mathrm{h}^{-1}$, while continuous phase flow rates were between 0.3 and $30 \mathrm{~cm}^{3} \cdot \mathrm{h}^{-1}$. Flows of dispersed and continuous phase were supplied counter-currently through the square capillary, and the flows became cocurrent through the collection capillary; the experimental setup of the flow focusing microfluidic device and the expanded schematic illustrating droplet formation within the device are shown in Figure 1a.

(a)

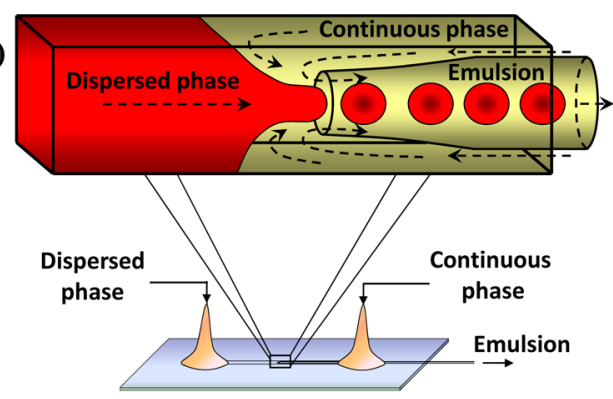

(b)

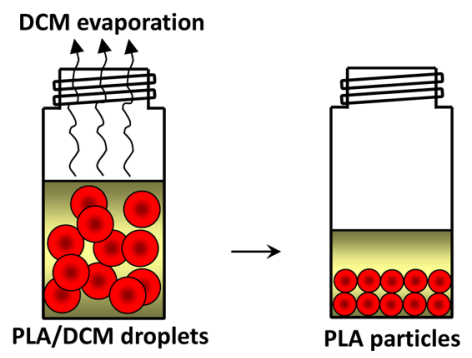

Figure 1. Glass capillary microfluidics/solvent evaporation method used to fabricate PLA particles. (a) Schematic diagram of experimental setup with expanded schematic of droplet formation in the flowfocusing region of the microfluidic device. (b) Formation of PLA particles from emulsion droplets by evaporation of dichloromethane (DCM) at room temperature.

DCM evaporates from PLA/DCM emulsions at ambient temperature to form shrunken, coherent PLA particles, as illustrated in Figure $1 \mathrm{~b}$. The time allowed for solvent evaporation was $24 \mathrm{~h}$.

\section{RESULTS AND DISCUSSION}

Breakup of the dispersed phase into monodisperse droplets occurs under dripping regime within the collection capillary at a depth of one orifice diameter from entrance, as shown by the video footage taken with the high speed camera at a rate of 2000 frames per second in Figure 2. The distance between the neighboring droplets progressively decreases as they move through the collection capillary, which is due to the decreasing rate of flow of the continuous phase as a result of a tapered shape of the collection capillary. At $t=0$, the thin liquid thread which connects the bulk dispersed phase and the droplet has just ruptured at two positions, leaving a small satellite droplet attached to the newly formed droplet. The bulk dispersed phase takes the shape of a sharp cone, while the droplet also exhibits a temporary nonspherical appearance, caused primarily by the attachment of the satellite droplet. Over the course of the next four frames, between $t=0.5$ and $2 \mathrm{~ms}$, the relatively short, conical appearance of the dispersed phase gives way to a more rounded, flat-sided cylindrical jet that extends over time into the orifice. Necking of the jet is shown over the course of the next three frames $(t=2.5-3.5 \mathrm{~ms})$, where the jet begins to thin because of the pressure exerted upon it by the continuous phase. This necking process continues until the dispersed phase is drawn into a narrow thread, which ruptures at $t=3.8 \mathrm{~ms}$ to complete the process of droplet formation. The mass balance equation can be used to predict the time of droplet formation: $t_{\mathrm{f}}$ 


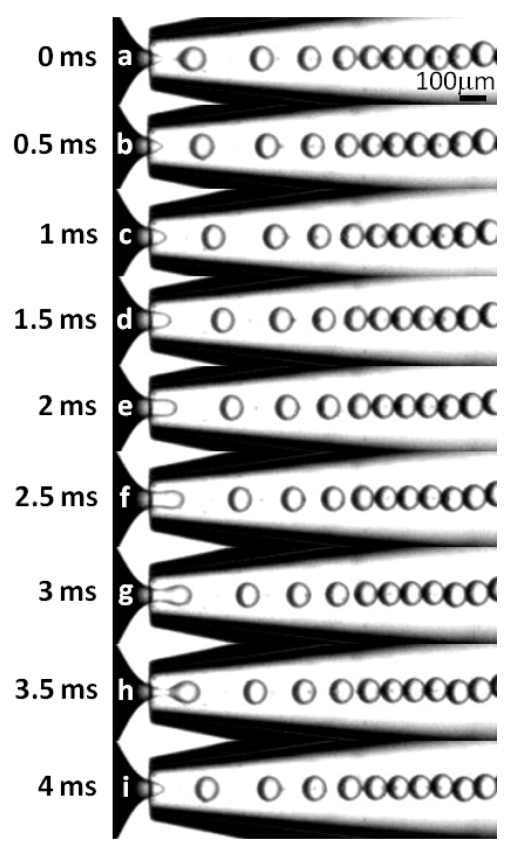

Figure 2. Experimental images of a drop breakup sequence in dripping regime at $Q_{c}=4 \mathrm{~mL} \cdot \mathrm{h}^{-1}$ and $Q_{d}=0.25 \mathrm{~mL} \cdot \mathrm{h}^{-1}$. The drop generation frequency and the drop diameter estimated from the footage were 262 $\mathrm{Hz}$ and $79 \mu \mathrm{m}$, respectively.

$=D_{\mathrm{d}}{ }^{3} \pi / 6 Q_{\mathrm{d}}$, where $Q_{\mathrm{d}}$ is the dispersed phase flow rate and $D_{\mathrm{d}}$ is the droplet diameter. By putting $Q_{\mathrm{d}}=2.5 \mathrm{~mL} \cdot \mathrm{h}^{-1}$ and $D_{\mathrm{d}}=$ $79 \mu \mathrm{m}$ into the above equation, we obtain $t_{\mathrm{f}}=3.7 \mathrm{~ms}$, which is close to the $t_{\mathrm{f}}$ value estimated from the footage.

The droplet size and generation rate can be varied by controlling the phase flow rates and device geometry, as shown by Figure 3. In Figure 3a, the orifice diameter $D_{\mathrm{o}}$ was $51 \mu \mathrm{m}$ and the flow rate ratio, $Q_{d} / Q_{d}$, was maintained at a relatively high level, so as to obtain small droplets with a diameter of 30 $\mu \mathrm{m}$ that have been converted into $12 \mu \mathrm{m}$ particles after DCM evaporation. In parts $\mathrm{b}$ and $\mathrm{c}$ of Figure 3 the device was the same but $Q_{c} / Q_{d}$ was reduced from 20 to 3.8 and 2.2, respectively, which led to increasingly larger droplets. Figure $3 c$ demonstrates a high stability of formed droplets to coalescence, despite high packing density in the collection tube. In addition, wetting of the collection tube by DCM was not observed, despite large droplet size. Droplets in Figure 3c are formed in the geometry-controlled regime, because the shear stress exerted by the continuous phase is small compared to interfacial stress. ${ }^{32}$ Under this regime, droplets grow in the collection tube until they occupy almost the entire cross section. To maintain the applied flow rate, a higher pressure is needed in the continuous phase stream in order to drive flow through a narrow gap between the tube wall and the droplet interface. The higher upstream pressure causes the continuous phase to squeeze the neck of the dispersed phase stream until breakup occurs. ${ }^{33}$

In Figure 3d, the dispersed phase flow rate was considerably higher than in Figure $3 a-c$ and this led to jetting. In Figure $3 a-c$, the continuous phase flows through the orifice faster than the dispersed phase, and the size of the formed droplets is predominantly determined by the balance between the drag of the continuous phase pulling the droplet downstream and interfacial tension force that resist the flow in the dispersed phase as pinch-off occurs. In Figure 3d, the dispersed phase flows within the orifice faster than the continuous phase $\left(u_{\mathrm{d}} \approx\right.$

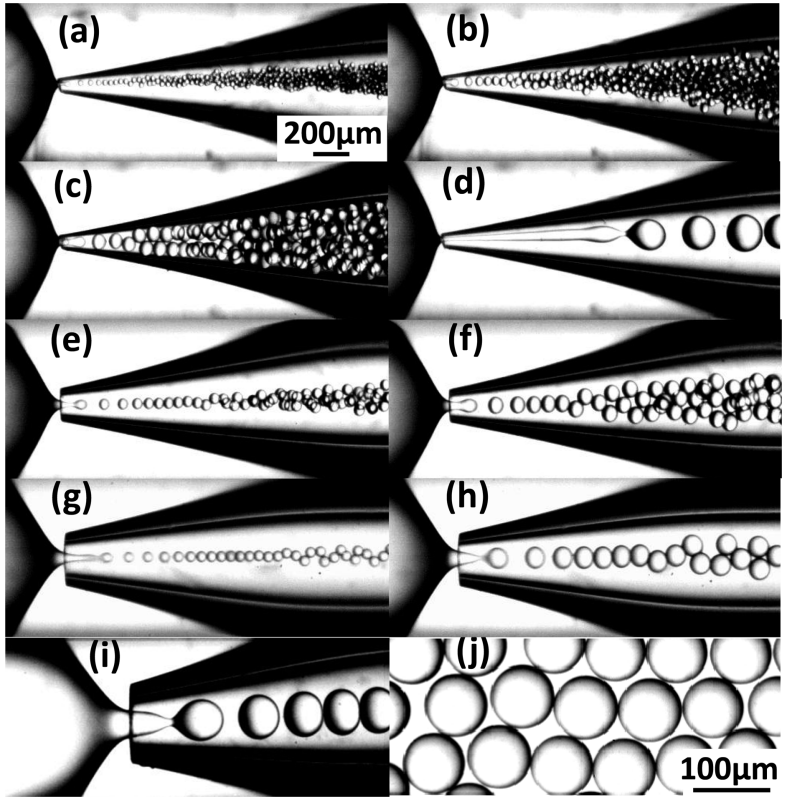

Figure 3. Experimental images of droplet formation under varying flow rates and orifice size: (a) $Q_{c}=0.6 \mathrm{~mL} \cdot \mathrm{h}^{-1}, Q_{d}=0.03 \mathrm{~mL} \cdot \mathrm{h}^{-1}, D_{\mathrm{o}}$ $=51 \mu \mathrm{m}, D_{\mathrm{d}}=30 \mu \mathrm{m}$; (b) $Q_{\mathrm{c}}=0.3 \mathrm{~mL} \cdot \mathrm{h}^{-1}, Q_{\mathrm{d}}=0.08 \mathrm{~mL} \cdot \mathrm{h}^{-1}, D_{\mathrm{o}}=$ $51 \mu \mathrm{m}, D_{\mathrm{d}}=50 \mu \mathrm{m}$; (c) $Q_{\mathrm{c}}=0.31 \mathrm{~mL} \cdot \mathrm{h}^{-1}, Q_{\mathrm{d}}=0.14 \mathrm{~mL} \cdot \mathrm{h}^{-1}, D_{\mathrm{o}}=51$ $\mu \mathrm{m}, D_{\mathrm{d}}=85 \mu \mathrm{m}$; (d) $Q_{\mathrm{c}}=2 \mathrm{~mL} \cdot \mathrm{h}^{-1}, Q_{\mathrm{d}}=0.53 \mathrm{~mL} \cdot \mathrm{h}^{-1}, D_{\mathrm{o}}=51 \mu \mathrm{m}$, $D_{\mathrm{d}}=206 \mu \mathrm{m}$; (e) $Q_{\mathrm{c}}=5.5 \mathrm{~mL} \cdot \mathrm{h}^{-1}, Q_{\mathrm{d}}=0.5 \mathrm{~mL} \cdot \mathrm{h}^{-1}, D_{\mathrm{o}}=111 \mu \mathrm{m}, D_{\mathrm{d}}$ $=59 \mu \mathrm{m}$; (f) $Q_{\mathrm{c}}=5 \mathrm{~mL} \cdot \mathrm{h}^{-1}, Q_{\mathrm{d}}=1 \mathrm{~mL} \cdot \mathrm{h}^{-1}, D_{\mathrm{o}}=111 \mu \mathrm{m}, D_{\mathrm{d}}=94$ $\mu \mathrm{m}$; (g) $Q_{\mathrm{c}}=13 \mathrm{~mL} \cdot \mathrm{h}^{-1}, Q_{\mathrm{d}}=0.4 \mathrm{~mL} \cdot \mathrm{h}^{-1}, D_{\mathrm{o}}=164 \mu \mathrm{m}, D_{\mathrm{d}}=60 \mu \mathrm{m}$; (h) $Q_{\mathrm{c}}=13 \mathrm{~mL} \cdot \mathrm{h}^{1}, Q_{\mathrm{d}}=1.9 \mathrm{~mL} \cdot \mathrm{h}^{-1}, D_{\mathrm{o}}=237 \mu \mathrm{m}, D_{\mathrm{d}}=132 \mu \mathrm{m}$; (i) $Q_{c}=20 \mathrm{~mL} \cdot \mathrm{h}^{1}, Q_{\mathrm{d}}=7.2 \mathrm{~mL} \cdot \mathrm{h}^{-1}, D_{\mathrm{o}}=216 \mu \mathrm{m}, D_{\mathrm{d}}=248 \mu \mathrm{m} ;(\mathrm{j})$ collected monodisperse droplets, $82 \mu \mathrm{m}$. The same scale bar applies to panels a-i.

$0.5 \mathrm{~m} \cdot \mathrm{s}^{-1}$ as compared to $\left.u_{\mathrm{c}} \approx 0.3 \mathrm{~m} \cdot \mathrm{s}^{-1}\right)$. As a result, it is the inertial force of the dispersed phase that must overcome the interfacial tension force; this balance is given by the Weber number of the dispersed phase, $W_{\mathrm{d}}=\rho_{\mathrm{d}} D_{i} u_{\mathrm{d}}^{2} / \gamma$, where $\rho_{\mathrm{d}}$ is the dispersed phase density, $D_{\mathrm{j}}$ is the jet diameter, $u_{\mathrm{d}}$ is the velocity of the dispersed phase in the orifice, and $\gamma$ is the interfacial tension. When $W_{\mathrm{d}}$ is small (e.g., $W_{\mathrm{d}} \approx 0.02$ in Figure $3 \mathrm{c}$ ), interfacial tension dominates, forcing the system to drip. ${ }^{34} \mathrm{By}$ contrast, at high Weber numbers, the inertial forces dominate interfacial tension force, leading to jetting (e.g., $W_{\mathrm{d}} \approx 3$ in Figure $3 d$ ). The orifices in Figure $3 e-h$ were larger than those in Figures $3 a-d$, but similar trends were observed with droplet sizes progressively increasing with decreasing flow rate ratio $Q_{d}$ $Q_{d}$ and increasing orifice size. Figure $3 \mathrm{j}$ shows monodisperse droplets with a diameter of $82 \mu \mathrm{m}$ collected shortly after being formed in a device with $130 \mu \mathrm{m}$ orifice. Droplets are packed into regular hexagonal arrays, as a result of a high degree of monodispersity, with a CV of less than $2 \%$.

To form PLA particles, an emulsion sample undergoes evaporation in air from a drop placed on a microscopic slide, as shown in Figure 4. Original PLA/DCM droplets with a diameter of $64 \pm 1 \mu \mathrm{m}$, an example of which is labeled a, are on the left-hand side of the figure. On the right-hand side lies the solvent evaporation front where evaporation proceeds via a 46 $\mu \mathrm{m}$ partly evaporated droplet, labeled $\mathrm{b}$, toward a coherent, PLA particle with $24 \pm 1 \mu \mathrm{m}$ diameter, labeled c. It should be noted that the presence of satellite droplets attached to larger droplets (c) is also visible in Figure 4. On the assumption of a 


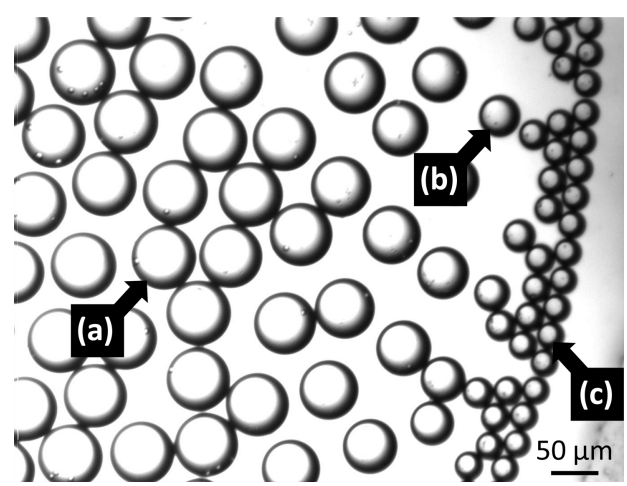

Figure 4. Optical micrograph showing PLA particles being formed from DCM/PLA droplets by evaporation from a microscopic slide: (a) $64 \mu \mathrm{m}$ emulsion droplet, (b) $46 \mu \mathrm{m}$ partly evaporated emulsion droplet, and (c) $24 \mu \mathrm{m}$ PLA particle.

complete DCM evaporation from droplets, the diameter of PLA particles is given by

$$
D_{\mathrm{p}}=\left[\left(x_{\mathrm{PLA}} /(1-\varepsilon)\right)\left(\rho_{\mathrm{d}} / \rho_{\mathrm{PLA}}\right)\right]^{1 / 3} D_{\mathrm{d}}
$$

where $x_{\mathrm{PLA}}=0.05$ is the mass fraction of PLA in the dispersed phase of the original emulsion, $\rho_{\mathrm{d}}=1310 \mathrm{~kg} \cdot \mathrm{m}^{-3}$ is the density of the dispersed phase, $\rho_{\text {PLA }}=1250 \mathrm{~kg} \cdot \mathrm{m}^{-3}$ is the density of solid PLA, $D_{\mathrm{d}}$ is the original droplet diameter, and $\varepsilon$ is the particle porosity. By putting $D_{\mathrm{d}}=64 \mu \mathrm{m}$ and $\varepsilon=0$ into eq 1 one obtains $D_{\mathrm{p}}=23.9 \mu \mathrm{m}$, which agrees well with the $D_{\mathrm{p}}$ value observed in Figure 4. Assuming $\varepsilon=0.05$, we obtain $D_{\mathrm{p}}=24.4$ $\mu \mathrm{m}$ from eq 1 , which is again in good agreement with the $D_{\mathrm{p}}$ value of $24 \mu \mathrm{m}$ observed in Figure 4 .

Figure $5 \mathrm{a}$ is an optical micrograph of aqueous suspension of PLA particles with a mean diameter of $23 \mu \mathrm{m}$ and a CV $<3 \%$. Figure 5b,c shows scanning electron micrographs of PLA particles with a mean diameter of $23 \mu \mathrm{m}$ showing a smooth surface with negligible porosity and spherical shape.

The droplet diameter, $D_{\mathrm{d}}$, can be controlled through the ratio of volumetric flow rates of dispersed to continuous phase, $Q_{c}$ $/ Q_{d}$, over the range of orifice diameters studied, as shown by the graph in Figure 6. For all orifice sizes used in this study, the observed droplet diameter decreased exponentially with flow rate ratio. The smaller the internal diameter of the orifice, the smaller the size of droplets produced for any given value of flow rate ratio which did not involve jetting. Droplets formed under jetting regime were considerably larger than those produced by dripping. The flow rate ratio that led to the jetting regime ranged from about 2 to 5, depending on orifice size. Figure 6 also shows that droplets of the similar size can be produced

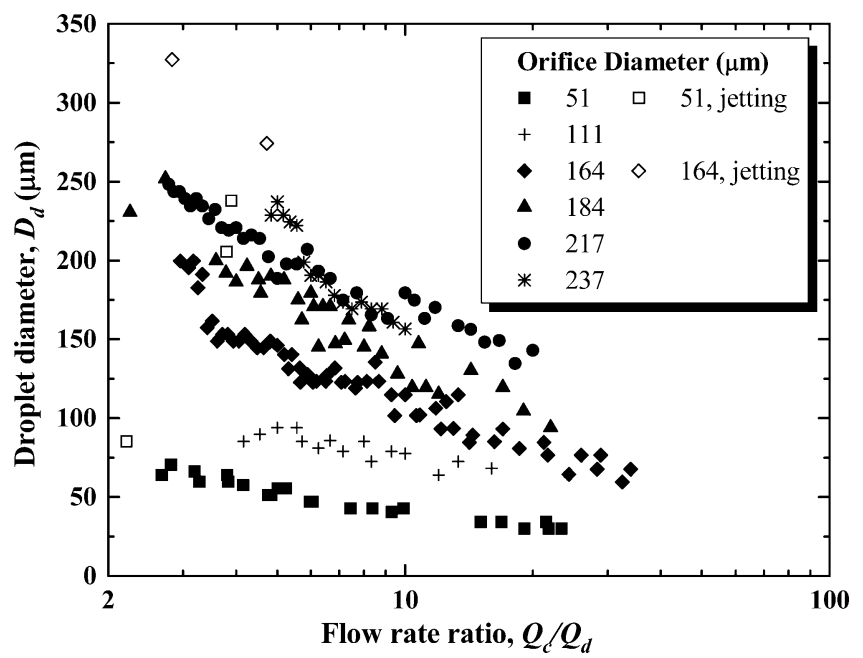

Figure 6. A semilog graph of droplet diameter, $D_{\mathrm{d}}$, versus ratio of volumetric flow rates of dispersed to continuous phase, $Q_{c} / Q_{d}$, over a range of orifice diameters. Filled symbols represent data points obtained under dripping regime, while open symbols represent data points obtained under jetting regime. Data arising from the device with the same orifice size are of the same shape.

from different orifice sizes, by varying phase flow rates, which shows high flexibility of our fabrication method.

Dripping and jetting have been observed in the same device under the same flow conditions, and the jetting-to-dripping transition was reversible and triggered by minor perturbations of the device or small periodic pulsations of the flow rates caused by the syringe pumps used in the experiments. Figure 7

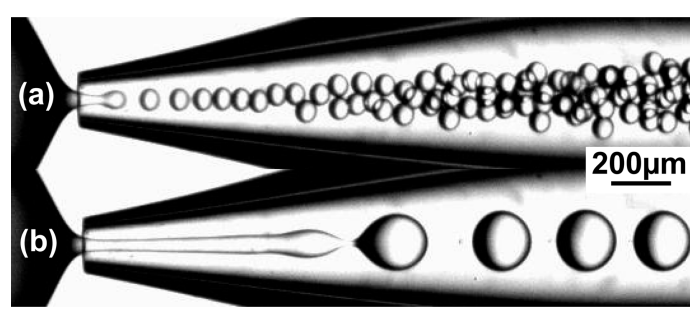

Figure 7. Experimental images of two different droplet formation regimes under identical operating conditions of $Q_{c}=6.5 \mathrm{~cm}^{3} \cdot \mathrm{h}^{-1} ; Q_{d}=$ $0.7 \mathrm{~cm}^{3} \cdot \mathrm{h}^{-1}$, and $D_{\mathrm{o}}=113 \mu \mathrm{m}$ : (a) droplets formed by dripping, $D_{\mathrm{d}}=$ $79 \mu \mathrm{m}, \mathrm{CV} \approx 2 \%$, and the ratio of jet length to orifice diameter, $L_{\mathrm{j}} / D_{\mathrm{o}}$ $\approx 1.1$; (b) droplets formed by jetting, $D_{\mathrm{d}}=200 \mu \mathrm{m}, \mathrm{CV} \approx 5 \%$, and $L_{\mathrm{j}} /$ $D_{\mathrm{o}} \approx 8.4$. The jet diameter at the entry section of the collection capillary was $47 \mu \mathrm{m}$ in both regimes. (a)

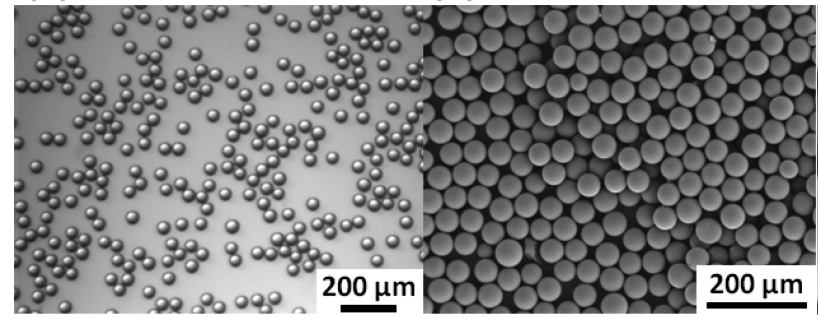

(c)

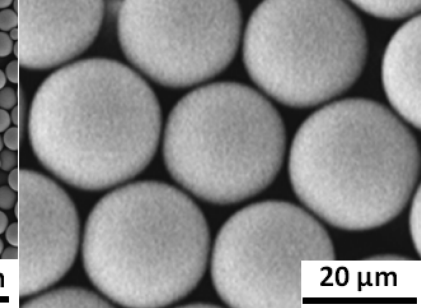

Figure 5. (a) Optical micrograph of aqueous suspension of $23 \mu \mathrm{m}$ PLA particles. (b, c) Scanning Electron Micrograph of $23 \mu \mathrm{m}$ PLA particles under different magnifications. 
displays images of droplet breakup taken in the same device under identical flow rate settings. The data shown here implies that the boundary between jetting and dripping is not sharply defined; instead, there is a transitional region where predominant dripping gives way to predominant jetting. Dripping shown in Figure 7a produced highly monodisperse droplets $(\mathrm{CV} \approx 2 \%)$ close to the orifice. In contrast, jetting shown in Figure $7 \mathrm{~b}$ produced a long widening jet that extended eight orifice diameters downstream into the collection tube, where it was broken into large drops. The location of necking in the jetting regime was less uniform than in the dripping mode, which led to greater variety in detachment location along the jet and more polydisperse droplets $(\mathrm{CV} \approx 5 \%)$. The average velocity of the dispersed phase at the entrance of the collection tube was $0.19 \mathrm{~m} \cdot \mathrm{s}^{-1}$ and the average velocity of the continuous phase surrounding the jet was $0.20 \mathrm{~m} \cdot \mathrm{s}^{-1}$. Therefore, dripping-to-jetting transition occurred when two immiscible phases passed through the collection tube at similar average velocities.

Figure 8 is a log-log plot of experimentally measured drop diameters scaled by the orifice diameter versus ratio of

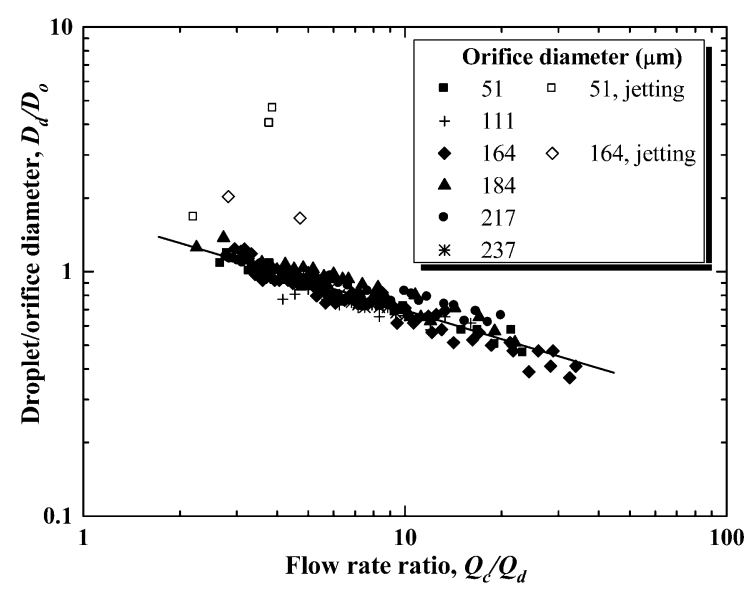

Figure 8. Droplet diameter/orifice diameter versus ratio of volumetric flow rates of dispersed to continuous phase over a range of orifice diameters. The experimental data shown on this graph are replotted from Figure 6. Filled symbols represent data points obtained under dripping regime, while open symbols represent data points obtained under jetting regime. Data arising from the device with the same orifice size are of the same shape. The equation of the straight line is $D_{\mathrm{d}} / D_{\mathrm{o}}=$ $A\left(Q_{c} / Q_{d}\right)^{B}$, where $A=0.23 \pm 0.01, B=-(0.39 \pm 0.01)$, and the correlation coefficient is $R=-0.938$.

volumetric flow rates of dispersed to continuous phase, $Q_{d}$ $Q_{\mathrm{d}}$. Experimental data follows a good linear trend with the following equation of the best fit straight line:

$$
D_{\mathrm{d}} / D_{\mathrm{o}}=0.23\left(Q_{\mathrm{c}} / Q_{\mathrm{d}}\right)^{-0.39}
$$

The exponent -0.39 in eq 2 is very close to the values of -0.37 and -0.40 obtained for generation of microbubbles in a 3D and planar flow focusing device, respectively. ${ }^{35,36}$ Droplets formed in the geometry-controlled regime had diameters in the range of $1.34 D_{\mathrm{o}}>D_{\mathrm{d}}>D_{\mathrm{o}}$, while droplets formed in the dripping regime had diameters $D_{\mathrm{o}}>D_{\mathrm{d}}>0.37 D_{\mathrm{o}}$. The most uniform droplets with a $\mathrm{CV}$ below $2 \%$ were obtained at flow rate ratios between 6 and 25 . At $Q_{c} / Q_{d}>25$, a good example of which is shown in Figure $3 \mathrm{~g}$, drops were formed from an elongated jet that was extended up to four orifice diameters downstream into the collection tube. The jet length increased with a further increase in $Q_{c} / Q_{d}$ until the dispersed phase was stretched into a long narrowing jet, but experimental data corresponding to this jetting mode were not included in Figure 8. Unlike jetting shown in Figures $3 \mathrm{~d}$ and $7 \mathrm{~b}$, which is characterized by a widening jet, this second class of jetting was characterized by a narrowing jet and led to formation of drops whose diameter was only slightly larger than that of the jet itself. Both types of jetting are characterized by formation of polydisperse droplets, and therefore, they are undesirable in practical applications.

The flow rate of the dispersed phase governs the frequency of generation of droplets at constant $D_{\mathrm{o}}$ and $Q_{c}$ values, as shown in Figure 9. The frequency of drop generation first

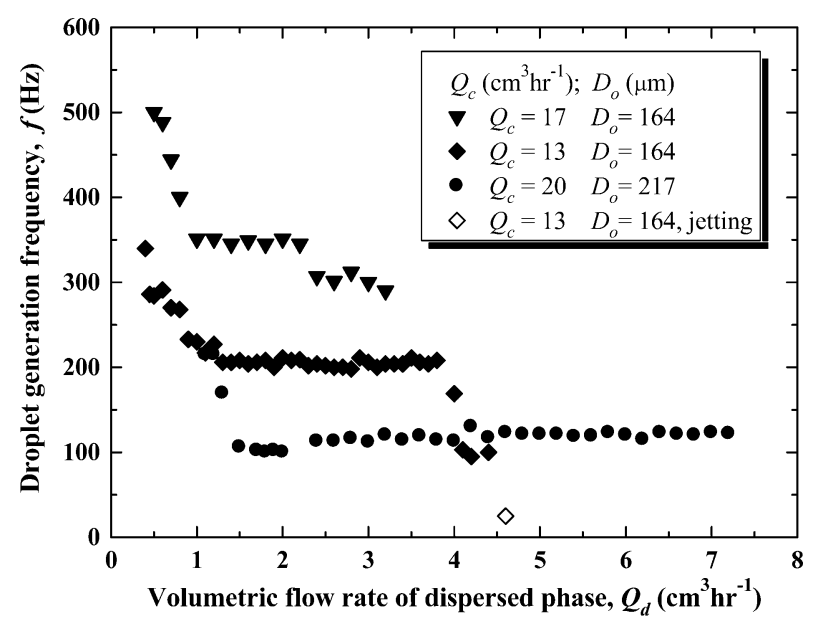

Figure 9. Graph of droplet generation rate versus volumetric flow rate of dispersed phase under constant continuous phase flow rate and orifice diameter values. Filled symbols represent data points obtained under dripping regime, while open symbols represent data points obtained under jetting regime. Data arising from the device with the same orifice size are of the same shape.

decreases as the flow rate of the dispersed phase increases, but it reaches a constant value at $Q_{\mathrm{d}}=1-1.5 \mathrm{~mL} \cdot \mathrm{h}^{-1}$ which corresponds to a transition from extended jet to dripping regime. Initially, $D_{\mathrm{d}} \propto Q_{\mathrm{d}}$, and because $f \propto Q_{\mathrm{d}} / D_{\mathrm{d}}{ }^{3}$, the relationship between $f$ and $Q_{d}$ becomes $f \propto Q_{d}{ }^{-2}$. In the dripping regime eq 2 can be applied and thus $D_{\mathrm{d}} \propto Q_{\mathrm{d}}{ }^{0.39}$; putting this equation into $f \propto Q_{\mathrm{d}} / D_{\mathrm{d}}{ }^{3}$ gives $f \propto Q_{\mathrm{d}}{ }^{-0.17}$, which means that the frequency of drop generation is virtually independent of the dispersed phase flow rate. In other words, any increase in drop formation time due to an increase in the diameter of the drops is fully compensated by the faster growth rate of droplets due to the increased rate of flow of the dispersed phase. At sufficiently high $Q_{d}$ values dripping gives way to jetting from a widening jet, and drop generation rate drastically decreases due to the rapid increase in the drop size.

\section{CONCLUSIONS}

We have developed a novel fabrication method for production of poly(lactic acid) particles based on glass capillary microfluidics and solvent evaporation. The size of the template droplets formed in flow focusing glass capillary devices has been closely controlled by phase flow rates and orifice size of the collection capillary. In the dripping regime, the ratio of droplet diameter to orifice diameter was inversely proportional to the 0.39 power of the flow rate ratio of continuous to dispersed phase. As the flow rate ratio increased, the diameter of the 
droplets produced in the device decreased to reach about $37 \%$ of the orifice diameter at the flow rate ratio of 34 . The most uniform droplets with a CV below $2 \%$ and a droplet to orifice size ratio ranging from 0.5 to 1 were produced at flow rate ratios ranging from 6 to 25. Monodisperse coherent PLA particles with a smooth surface were formed by DCM evaporation at room temperature, and the particle diameters were 2.7 times smaller than the initial droplet diameters. Two distinct classes of jetting characterized by a widening and narrowing jet have been identified at low and high $Q_{d} / Q_{d}$ values respectively, but they both led to polydisperse droplets. Our method can be used to fabricate particles from a variety of different biodegradable polymers, such as poly(lactic-coglycolic) acid, poly(caprolactone), tripalmitin, etc.

\section{AUTHOR INFORMATION}

\section{Corresponding Author}

*Phone: +441509222518. Fax: +441509223923. E-mail g. vladisavljevic@lboro.ac.uk.

\section{Notes}

The authors declare no competing financial interest.

\section{ACKNOWLEDGMENTS}

The work was supported by the Engineering and Physical Sciences Research Council (EPSRC) of the United Kingdom (grant reference number: $\mathrm{EP} / \mathrm{HO} 29923 / 1$ ).

\section{LIST OF SYMBOLS}

$\mathrm{CV}$ coefficient of variation

$D_{\text {o }} \quad$ orifice diameter, $m$

$D_{\mathrm{d}} \quad$ droplet diameter, $\mathrm{m}$

$D_{\mathrm{j}} \quad$ jet diameter, $\mathrm{m}$

$D_{\mathrm{p}}$ particle diameter, $\mathrm{m}$

$L_{\mathrm{j}} \quad$ jet length, $\mathrm{m}$

$Q_{c} \quad$ volumetric flow rate of continuous phase, $\mathrm{m}^{3} \cdot \mathrm{s}^{-1}$

$Q_{d} \quad$ volumetric flow rate of dispersed phase, $\mathrm{m}^{3} \cdot \mathrm{s}^{-1}$

$t_{\mathrm{f}} \quad$ droplet formation time, $\mathrm{s}$

$u_{\mathrm{d}}$ average velocity of dispersed phase in collection tube, $\mathrm{m} \cdot \mathrm{s}^{-1}$

$u_{\mathrm{c}}$ average velocity of continuous phase in collection tube, $\mathrm{m} \cdot \mathrm{s}^{-1}$

$W_{\mathrm{d}} \quad$ Weber number of dispersed phase

$x_{\text {PLA }}$ mass fraction of PLA in dispersed phase

$\varepsilon \quad$ porosity of PLA particle

$\gamma \quad$ interfacial tension, $\mathrm{N} \cdot \mathrm{m}^{-1}$

$\rho_{\mathrm{d}} \quad$ density of dispersed phase, $\mathrm{kg}^{3} \cdot \mathrm{m}^{-3}$

$\rho_{\text {PLA }}$ density of solid PLA, $\mathrm{kg}^{3} \cdot \mathrm{m}^{-3}$

\section{REFERENCES}

(1) Tran, V. T.; Benoît, J. P.; Venier-Julienne, M. C. Why and How to Prepare Biodegradable, Monodispersed, Polymeric Microparticles in the Field of Pharmacy? Int. J. Pharm. 2011, 407, 1-11.

(2) Cui, W.; Bei, J.; Wang, S.; Zhi, G.; Zhao, Y.; Zhou, X.; Zhang, H.; $\mathrm{Xu}, \mathrm{Y}$. J. Preparation and Evaluation of Poly(L-lactide-co-glycolide) (PLGA) Microbubbles as a Contrast Agent for Myocardial Contrast Echocardiography. Biomed. Mater. Res. B Appl. Biomater. 2005, 73, 171-178.

(3) Schmidt, B.; Souza, I.; van Beek, A.; Bohmer, M. Adhesion and Ultrasound-Induced Delivery from Monodisperse Microbubbles in a Parallel Plate Flow Cell. J. Controlled Release 2008, 131, 19-26.

(4) Berkland, C.; Kim, K. K.; Pack, D. W. Fabrication of PLG Microspheres with Precisely Controlled and Monodisperse Size Distributions. J. Controlled Release 2001, 73, 59-74.
(5) Leach, W. T.; Simpson, D. T.; Val, T. N.; Yu, Z.; Lim, K. T.; Park, E. J.; Williams, R. O.; Johnston, K. P. Encapsulation of Protein Nanoparticles into Uniform-Sized Microspheres Formed in a Spinning Oil Film. AAPS Pharm. Sci. Technol. 2005, 6, E605-E617.

(6) Ito, F.; Makino, K. Preparation and Properties of Monodispersed Rifampicin-Loaded Poly(lactide-co-glycolide) Microspheres. Colloids Surf., B 2004, 39, 17-21.

(7) Meyer, R. F.; Rogers, W. B.; McClendon, M. T.; Crocker, J. C. Producing Monodisperse Drug-Loaded Polymer Microspheres via Cross-Flow Membrane Emulsification: The Effects of Polymers and Surfactants. Langmuir 2010, 26, 14479-14487.

(8) Lu, J.; Jackson, J. K.; Gleave, M. E.; Burt, H. M. The Preparation and Characterization of Anti-VEGFR2 Conjugated, Paclitaxel-Loaded PLLA or PLGA Microspheres for the Systemic Targeting of Human Prostate Tumors. Cancer Chemother. Pharmacol. 2008, 61, 997-1005.

(9) Álvarez, A. L.; Espinar, F. O.; Méndez, J. B. The Application of Microencapsulation Techniques in the Treatment of Endodontic and Periodontal Diseases. Pharmaceutics 2011, 3, 538-571.

(10) Hauff, P.; Seemann, S.; Reszka, R.; Schultze-Mosgau, M.; Reinhardt, M.; Buzasi, T.; Plath, T.; Rosewicz, S.; Schirner, M. Evaluation of Gas-Filled Microparticles and Sonoporation as Gene Delivery System: Feasibility Study in Rodent Tumor Models. Radiology 2005, 236, 572-578.

(11) Wang, D.; Robinson, D. R.; Kwon, G. S.; Samuel, J. Encapsulation of Plasmid DNA in Biodegradable Poly(D,L-lactic-coglycolic acid) Microspheres as a Novel Approach for Immunogene Delivery. J. Controlled Release 1999, 57, 9-18.

(12) Klibanov, A. L. Ultrasound Molecular Imaging with Targeted Microbubble Contrast Agents. J. Nucl. Cardiol. 2007, 14, 876-884.

(13) Mendoza-Muñoz, N.; Noriega-Peláez, E. K.; Nava-Arzaluz, M. G.; Mendoza-Elvira, S. E.; Ganem-Quintanar, A.; Quintanar-Guerrero, D. Preparation and in Vitro Evaluation of Poly(D,L-lactide-co-glycolide) Air-Filled Nanocapsules as a Contrast Agent for Ultrasound Imaging. Ultrasonics 2011, 51, 839-845.

(14) Böhmer, M. R.; Klibanov, A. L.; Tiemann, K.; Hall, C. S.; Gruell, H.; Steinbach, O. C. Ultrasound Triggered Image-Guided Drug Delivery. Eur. J. Radiol. 2009, 70, 242-253.

(15) Ashton, R. S.; Banerjee, A.; Punyani, S.; Schaffer, D. V.; Kane, R S. Scaffolds Based on Degradable Alginate Hydrogels and Poly(lactideco-glycolide) Microspheres for Stem Cell Culture. Biomaterials 2007, $28,5518-5525$.

(16) Shi, X.; Sun, L.; Jiang, J.; Zhang, X.; Ding, W.; Gan, Z. Biodegradable Polymeric Microcarriers with Controllable Porous Structure for Tissue Engineering. Macromol. Biosci. 2009, 9, 12111218.

(17) Chu, C. R.; Coutts, R. D.; Yoshioka, M.; Harwood, F. L.; Monosov, A. Z.; Amiel, D. J. Articular Cartilage Repair Using Allogeneic Perichondrocyte-Seeded Biodegradable Porous Polylactic Acid (PLA): A Tissue-Engineering Study. Biomed. Mater. Res. 1995, $29,1147-1154$

(18) Wang, Y.; Shi, X.; Ren, L.; Wang, C.; Wang, D. A. Porous Poly(lactic-co-glycolide) Microsphere Sintered Scaffolds for Tissue Repair Applications. Mater. Sci. Eng., C 2009, 29, 2502-2507.

(19) Bhardwaj, U.; Papadimitrakopoulos, F.; Burgess, D. J. A review of the Development of a Vehicle for Localized and Controlled Drug Delivery for Implantable Biosensors. J. Diabetes Sci. Technol. 2008, 2, 1016-1029.

(20) Bhardwaj, U.; Sura, R.; Papadimitrakopoulos, F.; Burgess, D. J. PLGA/PVA Hydrogel Composites for Long-Term Inflammation Control Following s.c. Implantation. J. Int. J. Pharm. 2010, 384, 78-86.

(21) Shive, M. S.; Anderson, J. M. Biodegradation and Biocompatibility of PLA and PLGA Microspheres. Adv. Drug Delivery Rev. 1997, $28,5-24$.

(22) Straub, J. A.; Chickering, D. E.; Church, C. C.; Shah, B.; Hanlon, T.; Bernstein, H. Porous PLGA Microparticles: AI-700, an Intravenously Administered Ultrasound Contrast Agent for Use in Echocardiography. J. Controlled Release 2005, 108, 21-32.

(23) Yan, C.; Resau, J. H.; Hewetson, J.; West, M.; Rill, W. L.; Kende, M. Characterization and Morphological Analysis of Protein-Loaded 
Poly(lactide-co-glycolide) Microparticles Prepared by Water-in-Oil-inWater Emulsion Technique. J. Controlled Release 1994, 32, 231-241.

(24) Zolnik, B. S.; Burgess, D. J. Evaluation of in Vivo-in Vitro Release of Dexamethasone from PLGA Microspheres. J. Controlled Release 2008, 127, 137-145.

(25) Lee, W. K.; Park, J. Y.; Yang, E. H.; Suh, H.; Kim, S. H.; Chung, D. S.; Choi, K.; Yang, C. W.; Park, J. S. Investigation of the Factors Influencing the Release Rates of Cyclosporin A-Loaded Micro- and Nanoparticles Prepared by High-Pressure Homogenizer. J. Controlled Release 2002, 84, 115-123.

(26) Böhmer, M. R.; Schroeders, R.; Steenbakkers, J. A. M.; de Winter, S. H. P. M.; Duineveld, P. A.; Lub, J.; Nijssen, W. P. M..; Pikkemaat, J. A.; Stapert, H. R. Preparation of Monodisperse Polymer Particles and Capsules by Ink-Jet Printing. Colloids Surf., A 2006, 289, 96-104.

(27) Kobayashi, I.; Iitaka, Y.; Iwamoto, S.; Kimura, S.; Nakajima, M. Preparation Characteristics of Lipid Microspheres Using Microchannel Emulsification and Solvent Evaporation Methods. J. Chem. Eng. Jpn. 2003, 36, 996-1000.

(28) Xu, Q.; Hashimoto, M.; Dang, T. T.; Hoare, T.; Kohane, D. S.; Whitesides, G. M.; Langer, R; Anderson, D. G. Preparation of Monodisperse Biodegradable Polymer Microparticles Using a Microfluidic Flow-Focusing Device for Controlled Drug Delivery. Small 2009, 5, 1575-1581.

(29) Continuous Fabrication of Monodisperse Polylactide Microspheres by Droplet-to-Particle Technology Using Microfluidic Emulsification and Emulsion-Solvent Diffusion. Soft Matter 2011, 7, 9894-9897.

(30) Takeuchi, S.; Garstecki, P.; Weibel, D. B.; Whitesides, G. M. An Axisymmetric Flow-Focusing Microfluidic Device. Adv. Mater. 2005, 17, 1067-1072.

(31) Utada, A. S.; Chu, L. Y.; Fernandez-Nieves, A.; Link, D. R.; Holtze, C.; Weitz, D. A. Dripping, Jetting, Drops, and Wetting: The Magic of Microfluidics. MRS Bull. 2007, 32, 702-708.

(32) Anna, S. L.; Mayer, H. C. Microscale Tipstreaming in a Microfluidic Flow Focusing Device. Phys. Fluids 2006, 18, 121512.

(33) De Menech, M.; Garstecki, P.; Jousse, F.; Stone, H. A. Transition from Squeezing to Dripping in a Microfluidic T-Shaped Junction. J. Fluid Mech. 2008, 595, 141-161.

(34) Utada, A. S.; Fernandez-Nieves, A.; Stone, H. A.; Weitz, D. A. Dripping to Jetting Transitions in Coflowing Liquid Streams. Phys. Rev. Lett. 2007, 99, 094502.

(35) Gañán-Calvo, A. M.; Gordillo, J. M. Perfectly Monodisperse Microbubbling by Capillary Flow Focusing. Phys. Rev. Lett. 2001, 87, 274501.

(36) Garstecki, P.; Gañán-Calvo, A. M.; Whitesides, G. M. Formation of Bubbles and Droplets in Microfluidic Systems. Bull. Pol. Acad. Sci.: Tech. Sci. 2005, 53, 361-372. 